\title{
Documento e informação audiovisual: bases conceituais numa perspectiva neodocumentalista
}

\author{
Francisco Edvander Pires Santos
}

Mestrando; Universidade Federal do Ceará, Fortaleza, CE, Brasil; edvanderpires@gmail.com

Maria Giovanna Guedes Farias

Doutora; Universidade Federal do Ceará, Fortaleza, CE, Brasil;

mgiovannaguedes@gmail.com

Luiz Tadeu Feitosa

Doutor; Universidade Federal do Ceará, Fortaleza, CE, Brasil;

tadeu.feitosa62@gmail.com

Lidia Eugenia Cavalcante

Doutora; Universidade Federal do Ceará, Fortaleza, CE, Brasil;

cavalcantelidiaeugenia@gmail.com

Jefferson Veras Nunes

Doutor; Universidade Federal do Ceará, Fortaleza, CE, Brasil;

jefferson.veras@yahoo.com.br

Resumo: Este trabalho discute a produção do documento e da informação audiovisual em emissoras de televisão a partir da perspectiva neodocumentalista, caracterizada, sobretudo, pela produção de documentos digitais. Trata-se de uma revisão de literatura sobre os principais conceitos de documento e documentação, com base em teóricos documentalistas que alicerçaram o rigor científico em Biblioteconomia e Ciência da Informação. O estudo analisa o construto teórico do neodocumentalismo a fim de entender a sua conceituação e introduzi-lo no seio da produção do documento audiovisual, com destaque para os recursos e as fontes de informação que subsidiam a documentação televisiva. Discorre acerca das dimensões que compõem os documentos audiovisuais: textual, sonora e visual, onde cada elemento possui significado e relevância própria enquanto informação. Contextualiza o ambiente das emissoras de televisão e apresenta os principais suportes físicos e digitais, dentre fitas magnéticas, discos e formatos de vídeo, que compõem os acervos dos centros de imagem. Discute a concepção do documento audiovisual nas empresas televisivas baseado na produção de documentos próprios, externos, primários, secundários e terciários. Conclui-se que há a necessidade de se desenvolverem estudos teórico-epistemológicos nacionais em Biblioteconomia e 
Ciência da Informação, que contemplem as especificidades do documento e da informação audiovisual.

Palavras-chave: Documentação. Neodocumentalismo. Documento audiovisual. Centro de imagens. Emissoras de televisão.

\section{Introdução}

As tecnologias de informação e comunicação favoreceram a transição do documento analógico para o digital. Em algumas situações, os acervos físicos foram até mesmo substituídos pelos acervos digitais, embora haja ambientes de informação onde prevalece a constituição de acervos híbridos. Dentre os documentos que constituem esses acervos estão os audiovisuais, cujo conteúdo informacional perpassa a fronteira da leitura unicamente feita em suportes de escrita ou de caráter verbal.

A informação audiovisual é dotada de sentidos múltiplos e, obviamente, passou por transformações ao longo dos anos. Tendo a fotografia e os filmes em película como formatos e suportes de origem, o seu surgimento foi consequência das atividades desenvolvidas nos veículos de comunicação então emergentes, dentre eles a televisão, e o documento audiovisual se tornou o produto do registro dessas atividades, servindo de evidência em diferentes contextos de uso.

Visando compreender esse universo, contextualizar a documentação audiovisual produzida em emissoras de televisão e lançar as bases para uma discussão científica sobre o tema, apresentamos uma revisão de literatura com aporte teórico referente à documentação e ao neodocumentalismo. Com a temática definida e delimitada, seguimos os passos da revisão de literatura propostos por Hohendorff (2014).

Para a busca e organização de materiais para a revisão de literatura, definimos as palavras-chave e os descritores por meio dos quais acessamos as publicações sobre o audiovisual, tanto em Comunicação quanto em Biblioteconomia e Ciência da Informação. Utilizamos os seguintes termos de 
pesquisa (em português, inglês e espanhol): informação audiovisual; documento audiovisual; documentação audiovisual; imagens em movimento; gestão da informação audiovisual; acervos audiovisuais; centro de imagens; arquivo de imagens; e centro de documentação televisiva. A literatura espanhola se sobressaiu nos resultados satisfatórios do processo de busca e nos conduziu a obras de autores como Caldera-Serrano e Arranz-Escacha (2013).

Entretanto, nosso primeiro contato com os conceitos sobre o audiovisual em Biblioteconomia e Ciência da Informação veio a partir das publicações de Smit (1993, 1996), que nos motivaram a pesquisar as nuances da produção do documento audiovisual. Numa vertente epistemológica, os textos trabalhados na disciplina Fundamentos Teóricos e Epistemológicos da Ciência da Informação (BUCKLAND, 1997; RODRÍGUEZ BRAVO, B., 2002), do Programa de PósGraduação em Ciência da Informação da Universidade Federal do Ceará, trouxeram contribuições na discussão sobre os conceitos de documento e a sua relação com o audiovisual. Nesse sentido, seguimos uma ordem relativamente cronológica dos fatos que caracterizaram o percurso do documento à Documentação como área, tendo em vista, principalmente, as contribuições de Paul Otlet, Suzanne Briet e Shiyali Ranganathan.

No que se refere aos aspectos históricos da Ciência da Informação, complementamos as leituras com as publicações de Araújo (2014) e Ranganathan (1971). Contudo, fez-se necessário recorrermos ao desenvolvimento da televisão enquanto veículo de comunicação (BRIGGS; BURKE, 2016; RIBEIRO; SACRAMENTO; ROXO, 2010), visando contextualizar o início da produção do documento audiovisual nesses ambientes.

A leitura do texto de Frohmann (2008), discutido no Grupo de Pesquisa em Competência e Mediação em Ambientes de Informação, também foi importante no construto teórico deste artigo, pois possibilitou um novo olhar acerca da documentação audiovisual, desta vez sob o viés neodocumentalista, cuja discussão se estende em consonância com as publicações de González de Gómez (2011) e Blanca Rodríguez Bravo (2002). 
A partir da obra de Ángel Rodríguez Bravo (2006), percebemos as dimensões que constituem a informação audiovisual em sua essência, a saber: textual, sonora e visual (JOLY, 2012; PRIMO; CABRAL, 2014; ROSE, 2015). Com isso, construímos um mapa conceitual que ilustra a produção do documento audiovisual à luz do neodocumentalismo, tendo como ponto de partida todos os vieses abordados pelos teóricos que embasaram a nossa revisão de literatura.

Por fim, destacamos a documentação televisiva como um dos acervos mais representativos em matéria de informação audiovisual, trazendo, primeiramente, as reflexões de Caldera-Serrano e Arranz-Escacha (2013) ao seguirmos na linha neodocumentalista, com muitas similaridades entre Espanha e Brasil no que concerne à realidade dos ambientes de informação audiovisual televisiva. Posteriormente, discutimos a categorização dos programas de TV (ARONCHI DE SOUZA, 2004), a partir da qual os documentos audiovisuais de emissoras de televisão são produzidos, favorecendo, assim, a setorização desses ambientes de informação.

Ilustramos essa setorização numa cadeia documentária para emissoras de $\mathrm{TV}$, com a finalidade de embasar o relato pragmático diante da teoria e epistemologia estudadas sobre informação e documentação audiovisual.

\section{Documentação e neodocumentalismo}

A discussão sobre documentação e neodocumentalismo se pauta na continuidade do registro da informação num determinado suporte, seja ele físico - caráter intrínseco ao conceito de documento - ou digital - gênese do paradigma neodocumentalista. Com o audiovisual, a produção documental está intimamente atrelada ao surgimento do rádio, do cinema e da televisão, veículos de comunicação que se complementam e que convergem desde sempre.

Buckland (1997) define o termo "documentação" como aquilo que se faz para ou com os documentos; entretanto, esse autor questiona até onde vai o limite do termo, bem como o significado de "documento" (BUCKLAND, 1997, 
p. 804). Nessa mesma publicação, também discute os fatores que possibilitaram chegar à Documentação enquanto área, a partir do conceito único de "documento", afirmando que foi necessário criar novas técnicas para dar conta do aumento da produção técnico-científica em meados do século XIX, produção esta que ia além das coleções de livros. Para este autor, o termo "bibliografia" foi colocado em xeque, pois se entendeu que não abarcava atividades como a reprodução de materiais, ou que denotava pesquisa unicamente de caráter histórico.

No início do século XX, o termo "documentação" foi consolidado na Europa como sinônimo de "bibliografia"; no entanto, após 1950, a "documentação" foi amplamente contemplada pela terminologia que surgia na época: Ciência da Informação, armazenamento, recuperação e gestão da informação. O foco, então, não era unicamente o acesso ao documento, mas sim à informação, ao conteúdo registrado no suporte. Apesar disso, Buckland (1997) retoma a discussão no caminho inverso: da Documentação enquanto área de volta ao "documento". Dessa forma, ele traz uma reflexão sobre o que poderia ser ou não um documento, já que a documentação surge como técnica para gerenciar os textos impressos. Mas, e os que não são textos impressos? (BUCKLAND, 1997).

Passando para as conceituações, normalmente os documentalistas definiam "documento" como sendo "qualquer expressão do pensamento humano", com o termo "documentação" amplamente difundido na Europa, especialmente na França e Inglaterra. Nos Estados Unidos, porém, os termos "the graphic record", por Jesse H. Shera, e "the generic book", por Louis Shores, eram muito utilizados como sinônimos de "documento". "Isso foi conveniente para estender o escopo do campo [Documentação] ao incluir imagens gráficas, fotográficas e audiovisuais.” (BUCKLAND, 1997, p. 805, grifo e tradução nossa).

Acerca da apresentação dos principais teóricos, Buckland (1997) inicia com a visão de Paul Otlet, destacando que este considerava que os documentos podiam ser tridimensionais, tais como as esculturas, sendo complementado pelo 
pensamento de Suzanne Briet, que considerava as peças de museus como documentos. Para Otlet (em seu tratado de 1934), os objetos são documentos desde que transmitam informação, isto é, que informem algo ao sujeito. Para Briet (em sua publicação de 1951), documentos são evidências preservadas e registradas, que visam representar, reconstruir ou demonstrar um fenômeno físico ou conceitual, como, por exemplo, “[...] uma estrela no céu não é documento, mas uma foto dessa mesma estrela, sim.” (BUCKLAND, 1997, p. 806, tradução nossa).

Segundo Araújo (2014), numa vertente científica, Otlet visualizou na Documentação uma nova disciplina. "Ela seria, para os arquivos, os museus, os centros de cultura e demais instituições que custodiavam registros humanos, aquilo que a bibliografia tinha sido para a biblioteconomia." (ARAÚJO, 2014, p. 101). Dentre essas instituições, em se tratando de audiovisual, estão, atualmente, os centros de imagem, que custodiam a produção televisiva, cinematográfica ou publicitária de empresas e organizações audiovisuais, preservando, assim, os documentos que são gerados a partir do desenvolvimento das atividades desses ambientes de informação, como resultado da "expressão do pensamento humano", da criatividade, da intenção de transformar o conhecimento tácito em explícito e de fazer do documento audiovisual uma evidência de caráter econômico, social, político, histórico, cultural, patrimonial e administrativo.

Prosseguindo na discussão sobre os teóricos documentalistas, Buckland apresenta Donker Duyvis (com publicação datada de 1942), que sucedeu Otlet na Federação Internacional de Documentação (FID), e sua concepção sobre documento é influenciada pela Antroposofia (alto nível de conhecimento que transcende para um mundo espiritual). Para ele, um documento é um repositório da expressão do pensamento, e o seu conteúdo possui um caráter espiritual. Ao trazer Ranganathan (baseado em sua obra de 1963), Buckland expõe que ele considerava documento os micropensamentos inseridos no papel (suporte) ou em outro material que pudesse ser transportado e preservado ao longo do tempo. Para o centro dessa discussão, convém destacar que Ranganathan (1971, p. 26) introduziu o conceito de "microdocumentos" e destacou que, na época, o 
bibliotecário falhava no que se referia a disponibilizar os documentos aos seus usuários, pois não se sabia ao certo como tratar os novos formatos e suportes documentais.

Sob o viés da Antropologia, o conceito de documento vai ao encontro do que foi exposto por Otlet: inclui achados arqueológicos, traços da atividade humana e outros objetos que não se destinavam à comunicação. Na vertente da Semiótica, o conceito de documento se inter-relaciona com o que foi exposto por Briet: o texto e o objeto enquanto significante estático também são considerados documentos, na medida em que provêm informação ao sujeito. $\mathrm{Ou}$ seja, o objeto físico e simbólico é um documento que transmite uma mensagem e que, por sua vez, converte-se em informação.

Por fim, Buckland (1997) retoma a visão de Briet adaptando-a ao contexto dos sistemas de informação, que, segundo ele, podem ser usados não apenas para encontrar um material que já é uma evidência, mas também organizar esse material para que alguém o utilize como uma nova evidência para um propósito específico. O autor ressalta, ainda, que a discussão sobre o documento em suporte físico deve ser retomada, levando-se em consideração o avanço do ambiente digital na década de 1990.

Na dualidade físico-digital, que nos leva a refletir sobre a constituição de acervos híbridos, tais como os de caráter audiovisual, Frohmann (2008, p. 30) lança as bases do neodocumentalismo: "Os documentos digitais são significativamente diferentes de todos esses [analógicos], de muitas maneiras. Eles são casos paradigmáticos de um novo tipo de documentação". Desse modo, entram em pauta os documentos produzidos digitalmente e aqueles que são digitalizados, ou mesmo digitalizáveis. Exemplos disso são: o upload de arquivos em PDF em repositórios digitais; o tratamento dado a fotografias impressas e digitais; a microfilmagem de reportagens veiculadas em jornal impresso; as matérias de jornais que já nascem digitais; a conversão do conteúdo de uma fita VHS (em seu formato analógico) para DVD; a captura, feita quando se passa para o computador, de imagens em movimento a partir de fitas DV ou 
de outros suportes; o gerenciamento de imagens compartilhadas em rede, dentre outras situações.

Outro nome bastante representativo nesse paradigma é o de Blanca Rodríguez Bravo (2002), que, na perspectiva europeia denominada Ciência da Documentação, mas relacionada com a Ciência da Informação, apresenta quatro razões que justificam a discussão em torno dos conceitos de documento. $\mathrm{Na}$ primeira delas, a autora nos conduz à reflexão se o documento é o objeto da ciência à qual ela atribui o seu nome, isto é, Ciência da Documentação, ou se o objeto dessa ciência é a informação que o documento traz em si (RODRÍGUEZ BRAVO, B., 2002, p. 13).

A mensagem transmitida a partir do desenvolvimento dos documentos digitais embasa a segunda razão exposta por Blanca Rodríguez Bravo (2002), pois ela afirma que as tecnologias de informação e os processos de digitalização permitem a recuperação do conteúdo informacional independente do seu suporte de arquivamento original. Além disso, a autora explora as diferenças entre os conceitos de "documento", "fontes de informação" e "recursos de informação" (RODRÍGUEZ BRAVO, B., 2002).

A terceira razão da autora complementa a segunda, no sentido de esmiuçar a terminologia que permeia o conceito de documento, a saber: suporte, material, expressão, mensagem e informação, agrupando esses termos de acordo com o suporte ou meio utilizado para representar a mensagem, sejam documentos bibliográficos, textuais, audiovisuais, eletrônicos, digitais, especiais, dentre outras terminologias existentes.

A quarta e última razão concerne à produção do documento digital, pois ele "[...] tem transformado as unidades de informação [ou os centros de documentação] e procede refletir sobre a necessária integração do universo digital com o analógico" (RODRÍGUEZ BRAVO, B., 2002, p. 15, tradução nossa). A partir disso, a autora discute os conceitos e as características dos documentos digitais, comparando-os aos suportes analógicos, e aborda questões referentes aos suportes dos documentos digitais, às definições de hiperdocumento ou documento hipertextual, às linguagens de marcação ou 
etiquetas (Markup Language), aos aspectos que norteiam a edição digital e aos arquivos e bibliotecas digitais (RODRÍGUEZ BRAVO, B., 2002). Como alguns dos pontos da conclusão de sua publicação, a autora corrobora a existência de ambientes híbridos de informação e o prenúncio do autoarquivamento, levando em consideração que, no contexto digital, os metadados auxiliam na descrição do documento.

Dessa forma, os centros de imagem das emissoras de televisão se caracterizam enquanto ambientes híbridos de informação, tendo em vista a convivência entre as mídias físicas de arquivamento e as imagens disponibilizadas digitalmente em rede. Então, essa constituição dos documentos e da informação audiovisual televisiva merece destaque à luz do neodocumentalismo em Biblioteconomia e Ciência da Informação. Nesse contexto, Frohmann (2008, p. 21-22) destaca que: “A documentação se torna o meio de materialização da informação. Estudar a documentação é estudar as consequências e os efeitos da materialidade da informação". Partindo desse ponto de vista, Frohmann é o nome mais representativo do neodocumentalismo (GONZÁLEZ DE GÓMEZ, 2011).

Diante desse contexto, de que forma materializar, numa perspectiva neodocumentalista, a informação audiovisual que era produzida analogicamente e que agora já nasce ou se converte em digital na sua essência?

\section{Documento e informação audiovisual}

Para responder a essa questão, precisamos considerar o cenário no qual se deram o surgimento e a consolidação dos veículos de comunicação, mais especificamente o rádio, o cinema e a TV. A partir do surgimento desses meios, entre o final do século XIX e a primeira metade do século XX, na Europa e nos Estados Unidos, iniciou-se a formação de acervos físicos compostos pela produção de mensagens, fotografias e filmes, alicerces para a origem das imagens em movimento, das grandes salas de cinema e das exibições televisivas (BRIGGS; BURKE, 2016). No Brasil, o processo se deu entre as décadas de 1950 e 1970, quando os primeiros canais de televisão estruturaram a sua 
programação com base no improviso, na fotografia e no rádio, enfrentando, ainda, incêndios de médias e grandes proporções, que culminaram, obviamente, na perda de toda uma produção documental (RIBEIRO; SACRAMENTO; ROXO, 2010).

Áudio, vídeo e texto sincronizados são os elementos que constituem o documento audiovisual, que, desde a sua origem, passou por significativas mudanças e transições. Tomemos como exemplo os primeiros filmes, que advieram da fotografia, passaram pela era das películas e que agora podem ser assistidos num alto padrão de qualidade de som e imagem. Os dispendiosos equipamentos de TV, caracterizados como recursos de informação (RODRÍGUEZ BRAVO, B., 2002), exigiram cada vez mais suportes, ou mídias de arquivamento, que possibilitassem a mesma qualidade de som e imagem. Nesse sentido, Briggs e Burke (2016) contextualizam todas essas transições com fatos e eventos históricos importantes, na medida em que a Documentação já demonstrava, à luz de Otlet, Briet e Ranganathan, uma preocupação com esse tipo de material produzido.

A produção do documento a partir de áudio e imagens em movimento deve estar relacionada às fontes e aos recursos de informação disponíveis. Assim, "Podemos dizer que todo documento é uma fonte de informação, mas nem todas as fontes de informação são documentos." (RODRÍGUEZ BRAVO, B., 2002, p. 98, tradução nossa). Destacamos aqui os centros de imagem e demais ambientes de informação audiovisual, que se caracterizam como fontes de informação, mas não como documentos. Contudo, o material gravado e arquivado nesses ambientes é considerado fonte de informação e documento em sua essência.

Acerca de recursos de informação, Blanca Rodríguez Bravo (2002) os diferencia das fontes pelo fato de se constituírem como um bem e por estarem relacionados ao aparato tecnológico que subsidia a produção do documento. Segundo a autora, eles não devem ser geridos como os demais recursos de uma empresa, pois se distinguem por seu valor informativo. Como exemplo, temos um cartão de memória ou uma fita DV virgem que sai para a gravação de 
imagens de externa: ambos são recursos de informação, pois tiveram um valor monetário e se constituem em um bem adquirido pela empresa televisiva. No entanto, esse mesmo cartão e essa mesma fita gravados com material bruto ou editado são documentos que se tornam fontes de informação.

Sob a visão neodocumentalista, cabe analisar a produção de um documento audiovisual a partir dos seus elementos dissociados (áudio, vídeo e texto) e, em seguida, visualmente sincronizados. Ao expressar o pensamento humano, é necessário, primeiramente, roteirizar (cinema), construir uma pauta específica (telejornalismo) ou registrar uma ideia (campanha publicitária) ou um desenho (animação) no papel, onde a dimensão textual irá nortear os meandros da produção audiovisual. Na sequência, entram em cena os recursos de informação, tais como câmeras, microfones, softwares de edição etc., para que a captação de som e imagem seja possível, mediante a sincronização entre os elementos, e para que o documento seja gerado e, assim, a informação materializada. O produto final pode ser um documentário, um curta ou longametragem, uma reportagem, uma propaganda, uma animação, dentre outros gêneros e formatos cinematográficos ou televisivos (ARONCHI DE SOUZA, 2004).

Ao materializar a informação (FROHMANN, 2008), o texto está presente em todas as etapas de produção do documento audiovisual, tendo em vista que, como vimos, é a base para que a ideia seja desenvolvida. Contudo, após o texto ter sido convertido para o sonoro e o visual, estes dois elementos merecem destaque igualmente importante, seja de forma isolada ou conjunta, já que texto, áudio e vídeo sincronizam-se no processo de edição. E quando são editados ou analisados separadamente? Qual o potencial informativo de cada elemento na composição do documento audiovisual?

Consideramos, primeiramente, a dimensão sonora. Ángel Rodríguez Bravo (2006, p. 277), ao discutir de que forma o som contribui para a audiovisualidade, afirma que:

O áudio não atua em função da imagem e dependendo dela; atua como ela e ao mesmo tempo que ela [...] Convidamos o leitor a 
realizar a experiência de ver narrações audiovisuais eliminando o som e a ouvi-las eliminando as imagens.

$\mathrm{Na}$ edição do material, tanto o áudio original quanto os áudios sobrepostos (gravações de off ou trilha sonora sobre as imagens, por exemplo) poderão constituir a versão final do documento. Desse modo, o potencial informativo da dimensão sonora na produção audiovisual tem a mesma relevância como se estivesse sendo produzido exclusivamente para o rádio.

É possível inter-relacionar a publicação de Ángel Rodríguez Bravo (2006) com a perspectiva neodocumentalista. O autor expõe três linhas expressivas que definem a dimensão sonora; porém, discutiremos essas linhas como níveis de potencial informativo atribuído ao áudio. São elas: transmissão de sensações espaciais com precisão; possibilidade de interpretação do conjunto audiovisual; e organização narrativa, e também descritiva, do fluxo do discurso audiovisual.

Os ambientes e a tecnologia em voga definem a transmissão de sensações espaciais. Para Ángel Rodríguez Bravo (2006), essa concepção se refere à alta qualidade de apresentação e intensidade do som, seja numa sala de cinema, seja em outros locais de exibição do conteúdo audiovisual. Documentalmente, complementaremos esse conceito levando em consideração a fidedignidade do áudio em representar o ambiente, cenário ou situação presentes nas imagens. Essa produção, assim como todos os elementos do audiovisual, é feita a partir da subjetividade dos indivíduos, tais como editores de texto e de imagem, repórteres, produtores, roteiristas, dentre outros profissionais, e requer uma parcela devida de atenção no sentido de que imagem e som estejam perfeitamente sincronizados e fiéis à realidade retratada na gravação.

Acerca da possibilidade de interpretação do conjunto audiovisual, o autor enfatiza os efeitos sonoros sobre as imagens, destacando que as narrativas sonora e visual se complementam, pois "[...] a simbiose entre ambas configura uma mensagem nova, completamente diferente da transmitida por cada uma delas isoladamente.” (RODRÍGUEZ BRAVO, A., 2006, p. 278). Exemplo disso se dá na distinção entre acervos de imagens brutas e de material editado em 
emissoras de televisão. Nesses casos, um documento audiovisual poderá conter as imagens de um desastre natural sem que tenham passado por edição, então a mídia será arquivada como material bruto e, assim, o efeito sonoro original será preservado, sem cortes ou interrupções. Numa edição desse mesmo material, certamente haverá uma narração do fato por um repórter, alterando o significado original e a naturalidade da imagem, ou seja, configurando uma nova mensagem.

Por fim, a organização narrativa e descritiva do fluxo do discurso audiovisual se relaciona com as sequências lógicas do material em produção. $\mathrm{O}$ áudio deve demarcar o início e o fim de acordo com os planos, cenas e sequências estabelecidas na edição das imagens. Do contrário, teríamos apenas uma sucessão de imagens em movimento sem qualquer lógica de narração, pois o texto não acompanharia a imagem, e a dimensão sonora seria vaga e confusa. Nesse sentido, “Os spots publicitários são exemplos paradigmáticos de conjuntos de materiais visuais que, sem o som, costumam se transformar em uma chuva de imagens completamente desordenadas [...]" (RODRÍGUEZ BRAVO, A., 2006, p. 279). Se a organização narrativa se dá na etapa de produção do audiovisual e, consequentemente, documental, a organização descritiva ocorre após o documento ser incorporado definitivamente ao acervo, pois ela se aplica aos processos de indexação e decupagem (SANTOS, 2013), nos quais a descrição do áudio se constitui em elemento essencial para a representação e recuperação de informação.

No que concerne à dimensão visual, Joly (2012) traz alguns dos principais conceitos e ideias acerca da imagem, desde a perspectiva filosófica de Platão até chegar às teorias da Semiótica. A autora destaca que a imagem "[...] indica algo que, embora nem sempre remeta ao visível, toma alguns traços emprestados do visual e, de qualquer modo, depende da produção de um sujeito [...]" (JOLY, 2012, p. 13). Essa afirmação vai ao encontro do conceito de referente, que pode ser definido como o objeto enfocado na imagem em movimento, o qual é representado na sequência de imagens; porém, não deve ser confundido com o objeto real, pois ele é apenas a sua representação. As imagens 
capturadas em externa ou em estúdio numa emissora de televisão, por exemplo, passam a ser uma representação do real, dos sujeitos, objetos, situações e eventos envolvidos na gravação, ou seja, referentes que serão sincronizados aos elementos texto e som na composição do documento audiovisual.

O referente visual pode ser entendido como uma espécie de norte para o sujeito que assiste ao material e, em alguns casos, constitui-se como o "núcleo" da imagem, como sendo a informação principal da mensagem que ela transmite, o que acaba por depender da interpretação de cada indivíduo e da forma como a imagem foi editada, sendo passível, portanto, de transformações que variam de acordo com o contexto em que a imagem foi gerada e documentada. Além disso, o visual tem caráter polissêmico e ambíguo, na medida em que uma mesma imagem pode ser utilizada em contextos distintos daquele em que fora produzida originalmente.

Primo e Cabral (2014) abordam os aspectos de composição das imagens em movimento: planos, ângulos, enquadramentos, distância focal, continuidade, ritmo, iluminação e cor. Essas expressões da dimensão visual estão interligadas diretamente aos movimentos de câmera e ao processo de edição de imagem. Cenas e sequências são estabelecidas visando ao produto final: as imagens que serão assistidas por um determinado público e que são gravadas num determinado suporte para fins de arquivamento e preservação.

Por outro lado, Rose (2015) aborda a dimensão visual na vertente metodológica de transcrição da imagem em forma de narrativa daquilo que é assistido, convertendo o visual em uma nova dimensão textual. $\mathrm{Na}$ visão da autora, levam-se em consideração as decisões sobre a descrição dos efeitos visuais e sonoros apresentados na imagem, pausas e hesitações na fala dos indivíduos, iluminação, trilha sonora, dentre outros elementos que caracterizam a informação audiovisual. Assim, Rose (2015) divide o seu método de análise de imagens em movimento da seguinte forma: seleção dos programas de TV, transcrição, codificação e translação (tradução). A transcrição considera a unidade de análise, isto é, o ponto específico a partir do qual se iniciará e se finalizará a análise de um determinado conteúdo. 


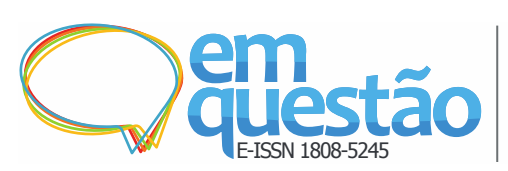

Documento e informação audiovisual: bases conceituais numa perpectiva neodocumentalista

Francisco Edvander Pires Santos, Maria Giovanna Guedes Farias, Luiz Tadeu Feitosa, Lidia Eugenia Cavalcante e Jefferson Veras Nunes

Diante de toda essa abordagem teórica, ilustramos, na Figura 1, a cadeia de produção do documento audiovisual na perspectiva neodocumentalista:

Figura 1 - Cadeia de produção do documento audiovisual à luz do neodocumentalismo

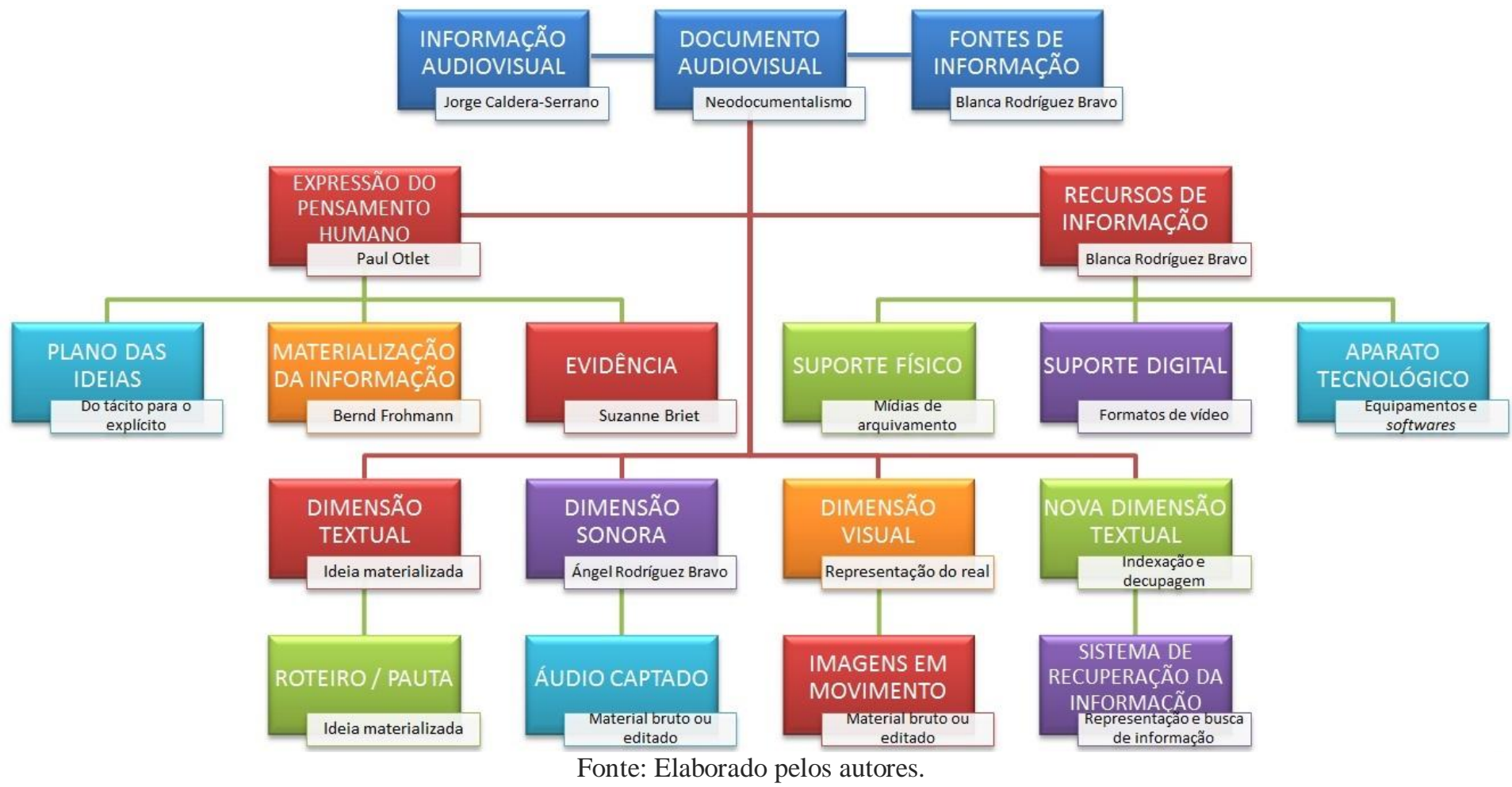

Essa cadeia representa as etapas de pré-produção, produção, pósprodução, arquivamento e descrição da informação audiovisual. Para conteúdo televisivo, o processo se inicia na dimensão textual, na qual a informação se materializa (FROHMANN, 2008) à medida que as ideias são colocadas no papel através da composição de um roteiro ou de uma pauta. Ao trazer do papel para a realidade, procede-se com a captação do áudio e das imagens em movimento, que representam as dimensões sonora (RODRÍGUEZ BRAVO, A., 2006) e visual (JOLY, 2012), respectivamente. Por fim, surge uma nova dimensão textual no momento da descrição da imagem (ROSE, 2015), ou seja, quando há a transcrição fidedigna do conteúdo produzido e registrado no documento audiovisual. 


\section{Documentação televisiva}

No Brasil, a produção documental televisiva se confunde com a própria implantação e consolidação das emissoras de TV. Em 1950, Assis Chateaubriand foi o responsável por importar essa tecnologia e, assim, pelo marco inicial de uma nova era na comunicação. Os investimentos foram altos, e o improviso assumiu lugar nas primeiras produções. Além dos programas de auditório e do formato noticioso trazido pelo rádio, as décadas de 1960 e 1970 foram marcadas por incêndios em diversas empresas televisivas, e isso fez com que parte do material produzido se perdesse e que houvesse a necessidade de se recomeçar praticamente do zero (RIBEIRO; SACRAMENTO; ROXO, 2010).

A variedade de programas que começaram a surgir nas décadas de 1970 e 1980 certamente consolidou o potencial informativo e a existência de massa documental, pois a expansão das redes de televisão para emissoras afiliadas possibilitou o auge no alcance da produção televisiva em cadeia nacional. Chegando à década de 1990, a televisão passara a ser uma realidade na maioria das casas dos brasileiros, e é possível inferir que os centros de documentação acompanharam esse ritmo. Nos anos 2000, viveu-se o alicerce da interatividade, e nos anos pós-2010, vivemos a era da convergência e da hiperinteratividade entre os veículos de comunicação, quando é nítido que o universo de imagens produzidas supera as décadas passadas.

Para Rosário (2009, p. 49), “É preciso considerar que o campo da televisão é constituído por um domínio heterogêneo, que se organiza, igualmente, sobre uma diversidade de linguagens". Entendemos que essa diversidade reflete as categorias, gêneros e formatos de programas de televisão no Brasil, conforme apontados por Aronchi de Souza (2004). Associamos a explanação do autor ao neodocumentalismo, tendo em vista que a produção do documento advém de todo o aparato tecnológico subsidiado pela empresa televisiva.

No que concerne aos recursos de informação, que possibilitam a produção documental televisiva, consideramos importante destacar os principais suportes ou mídias de arquivamento utilizadas nas gravações, numa ordem mais 
ou menos cronológica: películas; rolos Quadruplex e 8mm; fitas U-Matic; VHS; Betacam; Hi8; DVCPRO; DV; MiniDV; DVCam; MiniDVCam; XDCam; DVD; Blu-Ray; cartões de memória e HD, considerando também os storages. Nos acervos físicos, digitais ou híbridos constituídos por documentos audiovisuais, a avaliação do conteúdo informacional deve ser realizada periodicamente, pois há mídias que poderão ser eliminadas, sob a condição de uma cópia de segurança, devido ao seu uso em excesso, o que faz com que a imagem gravada comece a "dropar", isto é, a mídia perde a qualidade, começando a apresentar pontos, quadrados ou congelamentos na imagem.

Salientamos que essa eliminação vale apenas para as mídias utilizadas nas gravações de externa, ou seja, para as imagens capturadas quando a equipe de reportagem está na rua. Por outro lado, as mídias contendo os programas gravados terão a sua guarda permanente. Comenta-se muito sobre a qualidade dos diferentes tipos de suporte de arquivamento, bem como seu período de vida útil. Nesse quesito, há correntes de pensamento que defendem o arquivamento em suporte físico de todo o conteúdo produzido pela emissora, e que o material em cartões de memória ou em HD seja eliminado após o uso; em contrapartida, há quem defenda o arquivamento digital unicamente em rede, seja por HD ou storage, e que a mídia física seja abolida da rotina de trabalho das empresas televisivas $^{2}$. De uma maneira ou de outra, "Contar com um departamento de documentação já não é mais um luxo, e sim uma necessidade em todos os meios [de comunicação].” (CALDERA-SERRANO, 2014, p. 148, tradução nossa).

Ao discorrer acerca dos serviços de documentação nas empresas televisivas, Caldera-Serrano e Arranz-Escacha (2013) ressaltam, com base em exemplos reais, que os centros de imagem podem estar subordinados a diferentes departamentos, os quais variam de acordo com o organograma de cada emissora de TV, dentre eles: Direção de Produção, de Programação, de Operações, de Gerência e Comerciais, de Jornalismo etc. Essa estrutura organizacional não difere da brasileira; pelo contrário, sua semelhança possibilita o alcance de um padrão em sua rotina de trabalho. Assim, conforme o 
departamento ao qual o centro de imagens esteja subordinado, a sua estrutura interna (setorização) também poderá variar.

Complementando esse ponto, é importante descrever o workflow do ambiente de uma emissora de $\mathrm{TV}$, desde a concepção da pauta na redação à (re)utilização das imagens em novos materiais audiovisuais. Nesse sentido, Ayres, Silva e Santos (2011) trazem um modelo de cadeia documentária que representa a estrutura orgânica da maioria das empresas televisivas no Brasil, ilustrada na Figura 2:

Figura 2 - Cadeia documentária de uma emissora de televisão

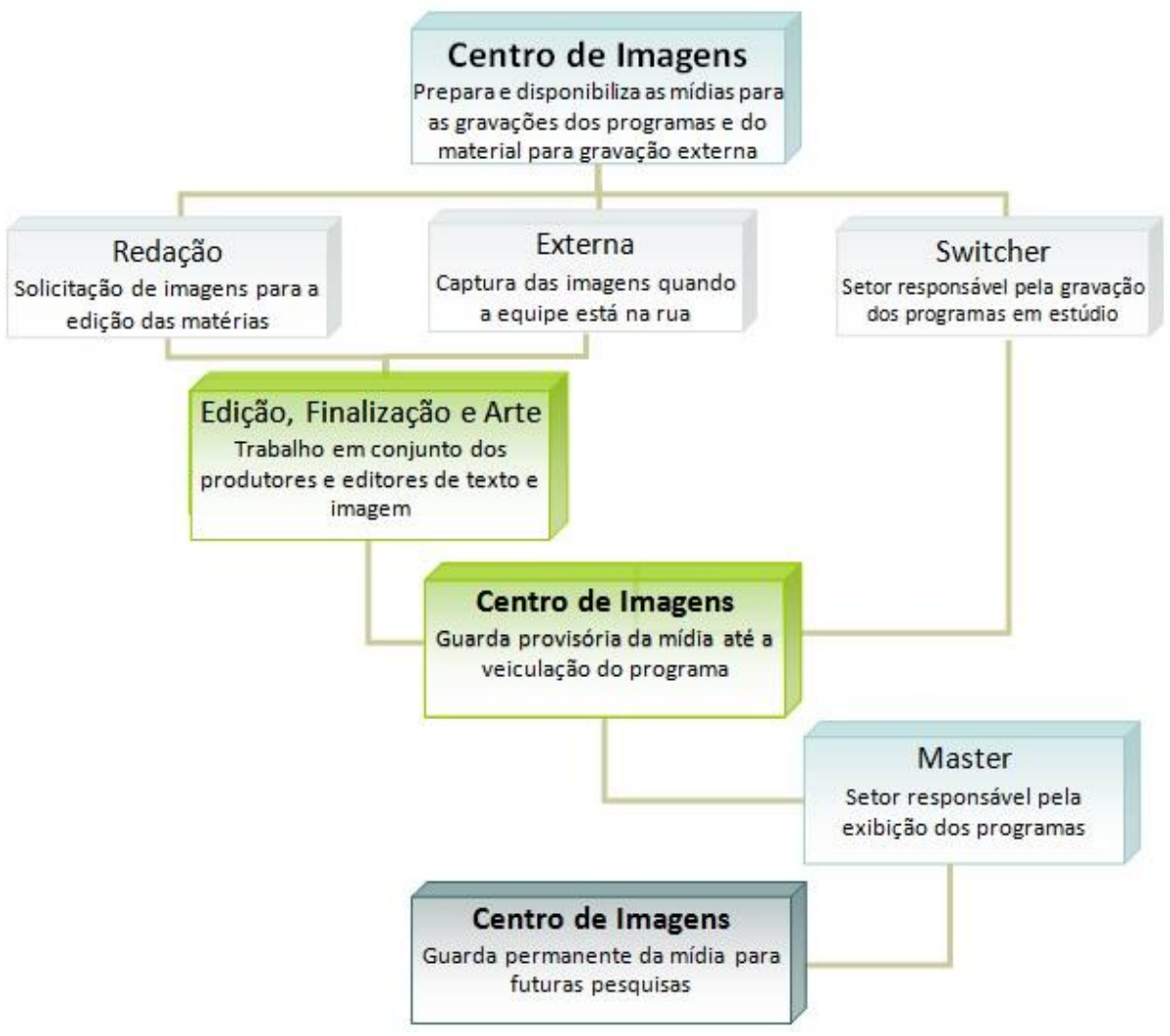

Fonte: Adaptado de Ayres, Silva e Santos (2011).

Ao observar atentamente a estrutura dessa cadeia, constatamos que o centro de documentação assume um papel estratégico não apenas nas atividades desempenhadas pelos setores da emissora, mas também embasando aspectos 
teóricos para pesquisa nesses ambientes de informação audiovisual ao levar em consideração o percurso do documento na instituição.

Podemos exemplificar quatro tipos de estrutura organizacional da qual fazem parte os centros de documentação de uma empresa televisiva (CALDERA-SERRANO; ARRANZ-ESCACHA, 2013): por tipo de atividade (que divide o serviço em dois setores: videoteca, responsável pelo preparo das mídias para gravações e pelo empréstimo das mídias arquivadas; e centro de documentação, responsável pela tomada de decisões gerenciais e representação da informação); por tipo de fundo documental (que divide e integra num único sistema os diferentes tipos de mídia: audiovisual, fotográfica, sonora e escrita); por tipo de programas (que define o organograma segundo as produções da emissora, dividindo-as em duas centrais: uma de entretenimento e outra de jornalismo, as quais se subdividem de acordo com o tipo de fundo documental, realidade semelhante à do Brasil); e por especialização de temática e de técnicas documentais (dividido, basicamente, em dois setores: o de representação da informação e o de atendimento ao usuário).

Caldera-Serrano e Arranz-Escacha (2013) caracterizam a produção audiovisual partindo da tipologia documental nos ambientes de televisão, dividindo-a segundo a entidade produtora dos documentos, bem como aquela que detém os direitos de imagem sobre eles, que contempla os documentos próprios e externos; e conforme o grau de produção da informação, que gera os documentos primários, secundários e terciários. Os documentos próprios são definidos como aqueles produzidos pela própria emissora, a partir de conteúdo próprio, dentre telejornais, reportagens, cobertura de eventos, programas de entretenimento etc., enquanto que os externos provêm de agências de notícias, produtoras independentes, profissionais freelance ou emissoras afiliadas.

Classificam-se como documentos primários aqueles que são gerados a partir de exibição ao vivo ou de imagens brutas (aquelas que chegam da rua, são descarregadas nas ilhas de edição, mas não passam pelo processo de edição). Os secundários trazem imagens que passaram por edição, gravações de off (narração de um repórter sobre uma imagem, por exemplo), montagem ou pós- 
produção, que, somente após esses processos, foram veiculadas pela emissora. Os documentos terciários são definidos pelos autores como sendo as "imagens de arquivo", ou seja, aquelas já existentes na TV e que estão sendo (re)utilizadas mediante solicitação prévia ao serviço de documentação da emissora, visando compor um novo material audiovisual a ser incorporado ao acervo, como uma reportagem, por exemplo. Essa realidade é vivenciada cotidianamente nas emissoras de televisão brasileiras, cuja variedade e produção documental crescem numa velocidade cada vez maior.

O valor da documentação audiovisual é discutido a partir de uma dupla dimensão: valor de exploração e valor patrimonial. Sobre o primeiro, os autores ressaltam a reutilização de imagens para a composição de um novo material audiovisual, como já mencionado anteriormente, o que gera economia para a emissora no que tange aos gastos com equipes de gravação em lugares longínquos, além da possibilidade de comercialização das imagens produzidas pela TV, gerando receita para algumas emissoras. No que se refere ao segundo valor, entra em discussão o caráter histórico dos documentos audiovisuais, reforçando a ideia de preservação do patrimônio audiovisual, tanto para a instituição quanto para a sociedade. Nesse contexto, os autores chamam a atenção para o fato de não haver, na Espanha, qualquer instituição que assuma a responsabilidade pela salvaguarda de todo o material (patrimônio) televisivo produzido no país, ao contrário do que ocorre, segundo eles, com o patrimônio audiovisual cinematográfico (na Espanha) e do que ocorre com a preservação de imagens de TV em países como a França. Quanto a isso, têm-se no Brasil TVs clipping, de caráter privado, em diversos estados brasileiros, que se responsabilizam por gravar toda a programação das emissoras no intuito de salvaguardar as imagens, mas nem sempre permanentemente, já que um dos objetivos é disponibilizá-las para clientes em potencial, mediante a comercialização.

Caldera-Serrano e Arranz-Escacha (2013) apresentam, ainda, as consequências do processo de digitalização dos documentos, com destaque para a substituição das mídias físicas pelos discos rígidos e cartões de memória, e dos 
usuários que delegam a busca pelos usuários (agora interagentes) em rede, que acessam as imagens compartilhadas em meio digital. Além disso, também são mencionados(as): a tecnologia streaming, a alta resolução das imagens, o autoarquivamento, a rapidez na seleção do que será arquivado permanentemente, o compartilhamento das imagens em tempo real e a convergência dos veículos/canais de comunicação, ao lançar mão da comercialização, da Web, dos dispositivos móveis e de outras tecnologias, ou seja, uma realidade que vai completamente ao encontro do paradigma neodocumentalista.

\section{Considerações finais}

Em bibliotecas e arquivos, os documentos audiovisuais são, por vezes, chamados de acervos não convencionais. No entanto, nos centros de imagem, eles mesmos constituem a massa documental produzida cotidianamente, exigindo, então, para além de estratégias e técnicas específicas de gestão, representação e mediação, estudos mais aprofundados em caráter teórico e epistemológico em Biblioteconomia e Ciência da Informação.

Essa documentação é constituída pela informação audiovisual, que, por sua vez, traz em seu conteúdo texto, áudio (sons, ruídos etc.) e vídeo (imagens em movimento) sincronizados e convertidos para uma nova dimensão textual, que ocorre quando as técnicas de indexação e decupagem (SANTOS, 2013) são colocadas em prática.

Apesar de termos abordado exclusivamente os ambientes televisivos, as características do documento e da informação audiovisual se estendem ao cinema, às agências de publicidade e até mesmo ao rádio. Nesse sentido, a tecnologia sempre esteve atrelada à produção documental nesses ambientes, desde o seu surgimento: primeiramente, a tecnologia que favoreceu a invenção do rádio, do cinema, da TV e da Internet; em seguida, a produção de massa documental que exigiu, com o passar do tempo, uma atenção especial por parte de profissionais e teóricos. 
De Otlet a Caldera-Serrano, percebemos que o documento audiovisual ganhou novas significações, desde ser considerado uma expressão do pensamento humano e uma evidência (documentação) até ganhar a conotação de materialidade e fonte de informação digital (neodocumentalismo). Constatamos, neste aspecto, uma lacuna teórico-epistemológica na Biblioteconomia e Ciência da Informação brasileiras no que tange ao documento audiovisual enquanto registro textual, sonoro e imagético, no qual as informações estão passíveis de múltiplas inferências e interpretações, a depender do contexto de uso do texto, do áudio e das imagens em movimento.

Dessa maneira, da documentação ao neodocumentalismo, a informação audiovisual sempre esteve propensa a ser digital em sua essência, ainda que, em seus primórdios, tenha sido produzida em suporte físico e analógico. Os elementos que a compõem se refletem em dimensões, conforme a teoria apresentada neste artigo: dimensão textual, sonora e visual, cada uma com elementos próprios a serem discutidos teoricamente e geridos documentalmente.

\section{Referências}

ARAÚJO, C. A. A. Arquivologia, Biblioteconomia, Museologia e Ciência da Informação: o diálogo possível. Brasília: Briquet de Lemos, 2014.

ARONCHI DE SOUZA, J. C. Gêneros e formatos na televisão brasileira. São Paulo: Summus, 2004.

AYRES, M. T. L.; SILVA, A. K. P.; SANTOS, F. E. P. Política de indexação do banco de dados do Jornal e da TV O POVO. Fortaleza, 2011.

BRASIL. Senado Federal. Manual de comunicação da Secom: glossário. Brasília, [201-?].

BRIGGS, A.; BURKE, P. Uma história social da mídia: de Gutenberg à Internet. Tradução: Maria Carmelita Pádua Dias; revisão técnica: Paulo Vaz. 3. ed. Rio de Janeiro: Zahar, 2016.

BUCKLAND, M. K. What is a "document"? Journal of the American Society for Information Science, Medford, v. 48, n. 9, p. 804-809, set. 1997. 
CALDERA-SERRANO, J. Resumiendo documentos audiovisuales televisivos: propuesta metodológica. Perspectivas em Ciência da Informação, Belo Horizonte, v. 19, n. 2, p. 147-158, abr./jun. 2014.

CALDERA-SERRANO, J.; ARRANZ-ESCACHA, P. Documentación audiovisual en televisión. Barcelona: Editorial UOC, 2013.

FROHMANN, B. O caráter social, material e público da informação. In: FUJITA, M. S. L.; MARTELETO, R. M.; LARA, M. L. G. (Org.). A dimensão epistemológica da Ciência da Informação e suas interfaces técnicas, políticas e institucionais nos processos de produção, acesso e disseminação da informação. São Paulo: FUNDEPE, 2008. p. 19-34.

GONZÁLEZ DE GÓMEZ, M. N. A Documentação e o Neodocumentalismo. In: CRIPPA, G.; MOSTAFA, S. P. Ciência da Informação e Documentação. Campinas: Alínea, 2011. cap. 2, p. 23-36.

HOHENDORFF, J. V. Como escrever um artigo de revisão de literatura. In: KOLLER, S. H.; COUTO, M. C. P. P.; HOHENDORFF, J. V. (Org.). Manual de produção científica. Porto Alegre: Penso, 2014. cap. 2, p. 39-54.

JOLY, M. Introdução à análise da imagem. 14. ed. Campinas, SP: Papirus, 2012.

PRIMO, L.; CABRAL, S. Produção audiovisual: imagem, som e movimento. São Paulo: Érica, 2014.

RANGANATHAN, S. R. Fifty years of experience in the development of Colon Classification. 1971.

RIBEIRO, A. P. G.; SACRAMENTO, I.; ROXO, M. (Org.). História da televisão no Brasil: do início aos dias de hoje. São Paulo: Contexto, 2010.

RODRÍGUEZ BRAVO, A. O som na narração audiovisual. In: RODRÍGUEZ BRAVO, A. A dimensão sonora da linguagem audiovisual. São Paulo: Editora SENAC, 2006. p. 271-336.

RODRÍGUEZ BRAVO, B. EI documento: entre la tradición y la renovación. Gijón: Ediciones Trea, 2002.

ROSÁRIO, N. M. Corpos eletrônicos em discurso de audiovisualidades. In: SILVA, A. R.; ROSSINI, M. S. (Org.). Do audiovisual às audiovisualidades: convergência e dispersão nas mídias. Porto Alegre: Asterisco, 2009. p. 45-65.

ROSE, D. Análise de imagens em movimento. In: BAUER, M. W.; GASKELL, G. (Org.). Pesquisa qualitativa com texto, imagem e som: um manual prático. 13. ed. Petrópolis: Vozes, 2015. p. 343-364. 
SANTOS, F. E. P. Documentos e informações audiovisuais: a teoria arquivística e as técnicas da Biblioteconomia aplicadas à organização de arquivos de TV.

DataGramaZero, Rio de Janeiro, v. 14, n. 5, out. 2013.

SMIT, J. W. A representação da imagem. Informare: Cadernos do Programa de Pós-Graduação em Ciência da Informação, Rio de Janeiro, v. 2, n. 2, p. 28-36, jul./dez. 1996.

SMIT, J. W. O documento audiovisual ou a proximidade entre as 3 Marias. Revista Brasileira de Biblioteconomia e Documentação, São Paulo, v. 26, n.1/2, p. 81-85, jan./jun. 1993.

\title{
Audiovisual document and information: conceptual bases under a neo documentation perspective
}

\begin{abstract}
This paper discusses how audiovisual documents and its information are produced in television stations under a neo documentation perspective, which is characterized by arising digital documents. It consists in a literature review about the main concepts of document and documentation that were thought by authors who studied them to contribute to the theoretical development in Library and Information Science. In this aspect, it analyzes the neo documentation theory focusing on understanding its concepts to introduce them as part of producing audiovisual documents, especially in television stations from the information sources and resources available. After that, it presents a discussion about three dimensions which compose audiovisual documents: text, sound and visual dimensions, where each one of those elements has own meaning and relevance to conceive the audiovisual information. Television stations are introducing in this study and the main kinds of tapes, discs and video file format are presented as documents that compose moving images collections. Thus, the conception of the audiovisual document in television stations is also presented based on producing own and external documents, as well as primary, secondary and tertiary documents. Finally, this paper concludes that it has been necessary to develop theoretical and epistemological studies in Brazilian Library and Information Science, focusing on the specificities of audiovisual documents and information.
\end{abstract}

Keywords: Documentation. Neo documentation. Audiovisual document. Moving images. Television stations. 
Recebido: 31/08/2017

Aceito: $14 / 11 / 2017$

${ }^{1}$ Do termo drop out (BRASIL, [201-?], doc. não paginado).

2 “Os vídeos analógicos são aqueles que foram gravados em mídias como fitas magnéticas. Esse tipo cedeu lugar para os vídeos digitais graças à evolução da tecnologia e ao fácil acesso aos dispositivos de captura. [...] Vale lembrar que o vídeo digital é aquele que pode ser manipulado em computador. Os formatos de arquivo mais comuns são MPEG, AVI e DivX. Para a TV Digital, o formato usado é o DVB e para o consumo são adotados os formatos DVD-Vídeo e Vídeo CD.” (PRIMO; CABRAL, 2014, p. 136). 